\title{
GMR
}

\section{Impact of early enzyme-replacement therapy for mucopolysaccharidosis VI: results of a long-term follow-up of Brazilian siblings}

\author{
J.F. Franco ${ }^{1}$, D.C. Soares ${ }^{1}$, L.C. Torres ${ }^{2}$, G.N. Leal ${ }^{1}$, M.T. Cunha ${ }^{1}$, \\ R.S. Honjo', D.R. Bertola ${ }^{1}$ and C.A. Kim ${ }^{1}$ \\ ${ }^{1}$ Unidade de Genética, Hospital das Clínicas, Faculdade de Medicina, \\ Universidade de São Paulo, São Paulo, SP, Brasil \\ ${ }^{2}$ Laboratório de Pesquisa Translacional, \\ Instituto de Medicina Integral Prof. Fernando Figueira, Recife, PE, Brasil \\ Corresponding author: C.A. Kim \\ E-mail: chong.kim@hc.fm.usp.br \\ Genet. Mol. Res. 15 (1): gmr. 15017850 \\ Received October 19, 2015 \\ Accepted December 7, 2015 \\ Published February 19, 2016 \\ DOI http://dx.doi.org/10.4238/gmr.15017850
}

\begin{abstract}
Mucopolysaccharidosis type VI (MPS VI) is an autosomal recessive multisystem lysosomal storage disorder, which is characterized by the deficiency of the enzyme arylsulfatase B encoded by the ARSB gene. Treatment of this disease with enzyme-replacement therapy (ERT) improves the clinical status of and generates hope for MPS VI patients. However, only few reports on patients with MPS VI treated before 5 years of age have been published. Thus, the objective of this study was to compare the clinical parameters of two sisters affected by MPS VI who started ERT at different ages (9 years and 1 year 5 months, respectively) and to determine the most relevant clinical impacts of early treatment after 85 months of evaluation. The treatment was well tolerated by both siblings. ERT in the younger sibling resulted in increased growth, an improved 6 -minute walk test, less coarse face, slower progression of cardiac valve
\end{abstract}


disease, and the absence of compressive myelopathy compared to that in her older sister. On the other hand, the older sibling had typical MPS VI phenotypic features before the commencement of ERT. Corneal clouding, clawed hands, and progressive skeletal changes were observed in both siblings despite the treatment. Both siblings displayed reduced frequencies of upper respiratory infections and apnea indices. This study emphasizes that early diagnosis and treatment of MPS VI are critical for a better disease outcome and to enhance the quality of life for these patients.

Key words: Enzyme-replacement therapy; Galsulfase; Glycosaminoglycan; Mucopolysaccharidosis; Arylsulfatase B; N-acetylgalactosamine-4-sulfatase

\section{INTRODUCTION}

Mucopolysaccharidosis type VI (MPS VI) or Maroteaux-Lamy syndrome (MIM 253200) is an autosomal recessive lysosomal storage disease. It is characterized by progressive multisystem involvement with reduced or lack of the activity of enzyme arylsulfatase B (ASB), also known as $\mathrm{N}$-acetylgalactosamine-4-sulfatase leading to incomplete degradation and cellular accumulation of the glycosaminoglycans (GAGs), dermatan sulfate (DS) and chondroitin sulfate (CS), within the lysosomes of the connective tissues (Harmatz et al., 2004; Giugliani et al., 2007). Defective ASB activity is determined by pathogenic variants in the ARSB gene located on chromosome 5 (5q135q14) (Litjens et al., 1989).

MPS VI patients present with a broad spectrum of clinical manifestations related to the progressive accumulation of GAGs and sulfated oligosaccharides derived from DS and CS in lysosomes, cells, and tissues that range from severe to relatively mild. The major clinical presentation of MPS VI includes a coarse face, growth retardation, dysostosis multiplex, and degenerative joint deformities. Other features include cardiac valve disease, reduced pulmonary function, upper airway obstructions, sinusitis, otitis media, hearing loss, carpal tunnel disease, inguinal and umbilical hernias, corneal clouding, and hepatosplenomegaly. Patients with MPS VI usually have normal intelligence, unlike the majority of those with other MPS types, but they may present with some important central nervous system complications, such as cervical cord compression, meningeal thickening, communicating hydrocephalus, optic nerve atrophy, and blindness (Guimaraes et al., 2010). This syndrome is usually characterized by significant functional impairment and a shortened lifespan.

In the past, there was no satisfactory treatment for MPS VI and few patients have benefited from bone marrow transplantation (Herskhovitz et al., 1999). Enzyme-replacement therapy (ERT) for MPS VI was approved in the United States for clinical purposes in 2005. Clinical trials of ERT have demonstrated rapid reductions in urinary GAG levels, improved endurance in walking and stair climbing tests, increased ranges of joint movement, and improved respiratory functioning (Harmatz et al., 2008).

Few studies have reported on the early initiation of ERT in affected individuals and there are only two reports in ERT for siblings with MPS VI younger than 5 years of age (McGill et al., 2010; Furujo et al., 2011; Muenzer, 2014). Thus, the objective of this report is to present two Brazilian siblings with MPS VI who began ERT at different ages ( 9 years and 1 year 5 months) and to determine the most relevant clinical impacts of the early treatment of this disorder. 


\section{MATERIAL AND METHODS}

\section{Sibling 1}

Sibling 1 was 8 years old at our initial evaluation and was the product of an uneventful pregnancy of healthy, consanguineous (first-degree cousins) parents. She was born at term with no intercurrence. Her birth weight was $3.7 \mathrm{~kg}$, she was $52 \mathrm{~cm}$ long, and her head circumference (HD) was $36 \mathrm{~cm}$. The first symptoms recognized by the family were coarse facial features when she was 2 years old. A biochemical diagnosis led to the detection of MPS VI when she was 3 years old. Molecular analysis of the ARSB gene identified the homozygous mutation c.1143-8T>G, which has been previously characterized in MPS VI patients (Petry et al., 2005; Garrido et al., 2008). At that time, she has already developed mitral and aortic lesions, along with a dilated and hypertrophic left ventricle. She underwent surgical treatment for glaucoma when she was 3 years old. She received surgical correction of an umbilical hernia when she was 4 years old. Her mitral valve was then replaced by a mechanical prosthesis and the aortic valve was surgically repaired when she was 8 years old. She presented frequent, recurrent upper respiratory tract infections. Her cognitive development was completely normal.

A physical examination at 8 years of age demonstrated a height of $98 \mathrm{~cm}(<5$ th percentile), weight of $15.5 \mathrm{~kg}(<5$ th percentile), and normal HD $(52.2 \mathrm{~cm})$. She also had a broad and coarse face, corneal opacities, a long philtrum, a large protruding tongue, a short neck, a narrow chest with a mild pectus carinatum deformity, a prominent abdomen, a lumbar gibbus deformity with stiffness, and contractures of several joints.

Skeletal X-rays revealed typical findings of dysostosis multiplex. Echocardiography showed pulmonary hypertension (systolic pressure of $51 \mathrm{mmHg}$ ), moderate aortic regurgitation, and mitral valve double lesions. Abdominal ultrasounds showed mild hepatomegaly. Urinary chromatography of GAGs revealed an increased DS fraction. Leukocyte assays demonstrated an ASB deficiency (4 $\mathrm{nmol} \cdot \mathrm{h}^{-1} \cdot \mathrm{mg}^{-1}$ protein; normal range: $44-106 \mathrm{nmol} \cdot \mathrm{h}^{-1} \cdot \mathrm{mg}^{-1}$ protein).

Weekly infusions of ERT with recombinant human ASB were started the age of nine. A dose of $1 \mathrm{mg} / \mathrm{kg}$ was prescribed weekly throughout the study period. She has been receiving the enzyme for 6.5 years (340 weeks) without adverse effects.

\section{Sibling 2}

Sibling 2 was born at term with no intercurrence. Her birth weight was $3.5 \mathrm{~kg}$, she was 49 $\mathrm{cm}$ long, and her HD was $36.5 \mathrm{~cm}$. The first symptoms recognized by the family were coarse facial features and joint stiffness at 7 months, which was earlier than that of her sister. The biochemical diagnosis of MPS VI was made soon after clinical suspicion. Molecular analysis of the ARSB gene identified the same homozygous variant found in her sister (c.1143-8T>G). Physical examination at 8 months of age revealed only a mildly coarse face with prominent cheeks with no other abnormalities, a weight of $9.5 \mathrm{~kg}$ (95th percentile), a height of $68.5 \mathrm{~cm}$ (75th percentile), and an HD of $45 \mathrm{~cm}$ (75th percentile). She had normal cognitive development.

Skeletal X-rays revealed abnormal J-shaped sella turcica, oar shaped ribs, gibbus malformation of the L1 vertebral body, hypoplastic and irregularly shaped carpal bones, hypoplastic radius and ulna, flaring of the diaphyseal canal of the long bones, and proximal pointed metacarpals. Echocardiography showed an enlarged left ventricle with compromised systolic function and mild 
pulmonary hypertension (systolic pressure of $37 \mathrm{mmHg}$ ). There was also a prolapsed posterior mitral leaflet with no signs of regurgitation or stenosis. Abdominal ultrasounds were normal. Urinary chromatography of GAGs revealed an increased DS fraction. Leukocyte assays showed an ASB deficiency (12.72 $\mathrm{nmol} \cdot \mathrm{h}^{-1} \cdot \mathrm{mg}^{-1}$ protein; normal range: $44-106 \mathrm{nmol} \cdot \mathrm{h}^{-1} \cdot \mathrm{mg}^{-1}$ protein).

In spite of the early diagnosis, enzyme therapy was only available when she was 1 year and 7 months of age. A dose of $1 \mathrm{mg} / \mathrm{kg}$ was prescribed weekly throughout the study period. She has been receiving the enzyme for 6.5 years ( 340 weeks) without adverse effects.

\section{Clinical evaluations}

Both sisters showed an improvement in upper airway obstruction, with a 50\% reduction in infection frequency. Furthermore, the apnea index (episodes/h) was much lower for sibling 2 (5.4) than for sibling 1 (16.1).

With regard to the facial dysmorphic features, sibling 2 presented a less coarse face than sibling 1 (Figure 1).
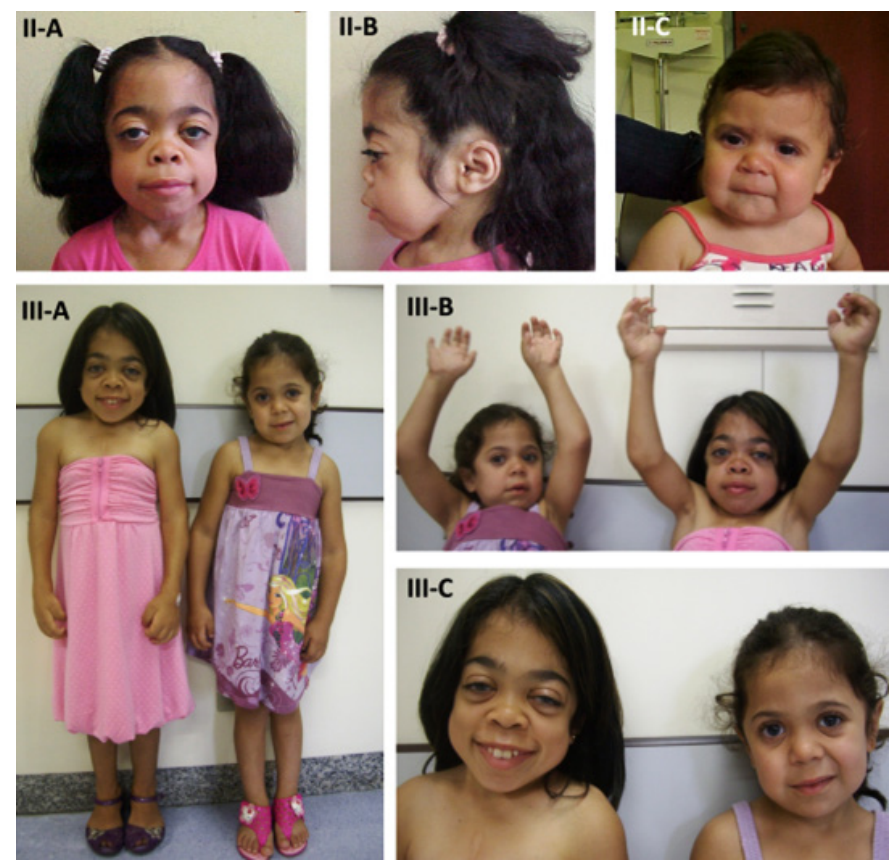

Figure 1. Sibling 1 with marked coarse faces at 8 years (II-A and II-B) and mild dysmorphisms in sibling 2 at 1.5 years (II-C), 6.5 years (III-A), and 13.5 years (III-B and III-C). Furthermore, the height and weight of sibling 1 was always lower than the normal reference values; however, sibling 2 maintained a normal rate of growth compared to growth rates in healthy children of the same age.

Corneal opacities and clawed hands were observed in both sisters at week 340 . The younger sister developed a moderate form of corneal opacity and the older sister developed a severe form. Both siblings presented severely clawed hands in addition to dysostosis multiplex. Sibling 1 was already severely affected at the age of 8 years and 9 months and sibling 2 developed a mild to moderate form at age 8 (week 340 of ERT). 
An MRI of the spine showed foramen magnum stenosis and compressive myelopathy in sibling 1 at week 340 (15 years), while sibling 2 remained normal (8 years 6 months).

A recent study reporting the cardiac abnormalities presented by both siblings showed that sibling 1 had mitral and aortic valve compromise at only 2 years of age and that she needed surgical intervention at 8 years of age, which was before she started ERT. Furthermore, sibling 2 developed mild mitral and aortic lesions throughout the follow-up period of 3 years. Both siblings had left ventricle cardiomyopathy; however, partial reverse remodeling was detected after 100 weeks of ERT (Leal et al., 2014).

Urinary GAGs were measured at 340 weeks after the first infusion of ERT, showing a reduction of $83 \%$ (655 to $178 \mu \mathrm{g} / \mathrm{mg}$ creatinine) in sibling 1 and $91 \%$ (1245 to $111 \mu \mathrm{g} / \mathrm{mg}$ creatinine) in sibling 2 (Figure 2).

Despite these reductions, the urinary GAG levels remained above the reference values.

GAGs

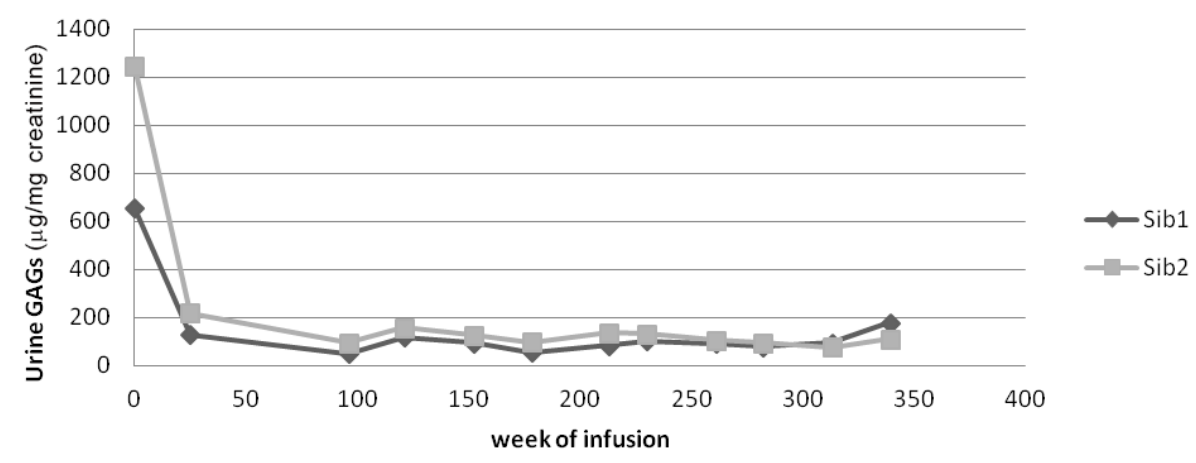

Figure 2. Decrease in absolute urinary GAG levels ( $\mu \mathrm{g} / \mathrm{mg}$ creatinine) for individual patients from baseline to week 340. Normal urine GAG values (mean SD) are age dependent: $<1$ year (133-274); $<2$ years $(79-256)$; $<5$ years $(67-$ $124) ;<7$ years $(53-115)$, and $<14$ years $(26-97)$.

The 6-minute walk test (6MWT) was performed by sibling 1 at weeks $73,122,173$, and 240. She consistently scored below the 3rd percentile on this test. This test was administered to sibling 2 twice (at weeks 173 and 240) because of her age at the beginning of the study. She scored within the normal range for healthy individuals of the same age for both evaluations. Her first assessment score was in the 75 th-90th percentile and her last assessment was in the $50^{\text {th }}-75$ th percentile.

\section{DISCUSSION}

ERT has been shown to have clinical benefits for MPS VI patients older than 5 years of age (Harmatz et al., 2006; Giugliani et al., 2007). However, the initiation of therapy before this age may have additional benefits and/or prevent some complications (McGill et al., 2010; Furujo et al., 2011; Horovitz et al., 2013). This study presents follow-up data for two Brazilian siblings diagnosed with MPS VI, enabling a comparison of clinical and laboratory outcomes of the effects of ERT initiated at different ages. 
It is interesting to note that MPS VI has a wide spectrum of clinical severity, primarily because of the effect of various mutations, some of which permit residual enzyme activity (Giugliani et al., 2007). The study of siblings, where the same mutations are present and intrafamilial variation is small, surely strengthens the importance of the results regarding early ERT.

ERT was well tolerated by both siblings. With regard to the growth parameters, the early introduction of ERT for sibling 2 (1 year 5 months) allowed for normal growth, and she even reached the height of her older sister (at 6 years 6 months and 13 years 6 months, respectively). Growth failure is characteristic of untreated MPS VI. Growth plate failure in MPS disease may be related to abnormal GAG storage in chondrocytes, leading to an inflammatory response, cell dysfunction, and death (Simonaro et al., 2001). With regard to the facial characteristics, sibling 2 had a less coarse face than sibling 1 (Figure 1). Hepatomegaly, which was present in sibling 1 at baseline, was not observed at week 340 .

Cardiac dysfunction is a significant cause of morbidity and mortality across the spectrum of MPS VI patients. As mentioned, a recent study conducted by our group showed that sibling 2 did not need surgical replacement of the mitral valve. Sibling 1 had undergone this procedure due to the worsening of mitral insufficiency even before starting ERT (Leal et al., 2014). These results suggest that the earlier initiation of ERT may limit the development or progression of cardiac valve disease. Furthermore, the two siblings had left ventricle cardiomyopathy and partial reverse remodeling was induced by ERT in both cases.

The normal scores achieved by sibling 2 on the 6MWT indicated an improvement in the distance walked between weeks 173 to 240 than that by sibling 1 and was even comparable with scores from healthy children. Importantly, there was a $50 \%$ reduction in the number of upper airway infections per year in both patients, which reduced the need for antibiotic therapy and improved their qualities of life.

Urinary GAGs are associated with lysosomal storage reduction in well-vascularized tissues, as has been observed in animal studies (Auclair et al., 2003). The response to ERT in this study is similar to that observed in other studies and the 10-20-fold reduction in GAGs observed in our patients after 340 weeks showed that administration of galsulfase was effective in removing these substrates (Swiedler et al., 2005).

\section{CONCLUSION}

Although ERT is not a curative treatment, it significantly improves various clinical aspects related to MPS VI. This study corroborates scientific evidence indicating that early diagnosis and treatment of this disorder are critical for a long-term favorable clinical outcome and for enhancing the quality of life of these patients.

\section{Conflicts of interest}

The authors declare no conflict of interest.

\section{ACKNOWLEDGMENTS}

We thank the patients and their parents for participating in this study. We also thank FAPESP (\#2010/52694-80) and CNPq, and BioMarin for their financial support. 


\section{REFERENCES}

Auclair D, Hopwood JJ, Brooks DA, Lemontt JF, et al. (2003). Replacement therapy in Mucopolysaccharidosis type VI: advantages of early onset of therapy. Mol. Genet. Metab. 78: 163-174. http://dx.doi.org/10.1016/S1096-7192(03)00007-6

Furujo M, Kubo T, Kosuga M and Okuyama T (2011). Enzyme replacement therapy attenuates disease progression in two Japanese siblings with mucopolysaccharidosis type VI. Mol. Genet. Metab. 104: 597-602. http://dx.doi.org/10.1016/j. ymgme.2011.08.029

Garrido E, Cormand B, Hopwood JJ, Chabás A, et al. (2008). Maroteaux-Lamy syndrome: functional characterization of pathogenic mutations and polymorphisms in the arylsulfatase B gene. Mol. Genet. Metab. 94: 305-312. http://dx.doi. org/10.1016/j.ymgme.2008.02.012

Giugliani R, Harmatz P and Wraith JE (2007). Management guidelines for mucopolysaccharidosis VI. Pediatrics 120: 405-418. http://dx.doi.org/10.1542/peds.2006-2184

Guimarães MdoC, de Farias SM, Costa AM and de Amorim RF (2010). Maroteaux-Lamy syndrome: orofacial features after treatment by bone marrow transplant. Oral Health Prev. Dent. 8: 139-142.

Harmatz P, Whitley CB, Waber L, Pais R, et al. (2004). Enzyme replacement therapy in mucopolysaccharidosis VI (MaroteauxLamy syndrome). J. Pediatr. 144: 574-580. http://dx.doi.org/10.1016/i.jpeds.2004.03.018

Harmatz P, Giugliani R, Schwartz I, Guffon N, et al. MPS VI Phase 3 Study Group (2006). Enzyme replacement therapy for mucopolysaccharidosis VI: a phase 3 , randomized, double-blind, placebo-controlled, multinational study of recombinant human $\mathrm{N}$-acetylgalactosamine 4-sulfatase (recombinant human arylsulfatase B or rhASB) and follow-on, open-label extension study. J. Pediatr. 148: 533-539.e6.

Harmatz P, Giugliani R, Schwartz IV, Guffon N, et al.; MPS VI Study Group (2008). Long-term follow-up of endurance and safety outcomes during enzyme replacement therapy for mucopolysaccharidosis VI: Final results of three clinical studies of recombinant human N-acetylgalactosamine 4-sulfatase. Mol. Genet. Metab. 94: 469-475. http://dx.doi.org/10.1016/j. ymgme.2008.04.001

Herskhovitz E, Young E, Rainer J, Hall CM, et al. (1999). Bone marrow transplantation for Maroteaux-Lamy syndrome (MPS VI): long-term follow-up. J. Inherit. Metab. Dis. 22: 50-62. http://dx.doi.org/10.1023/A:1005447232027

Horovitz DD, Magalhães TS, Acosta A, Ribeiro EM, et al. (2013). Enzyme replacement therapy with galsulfase in 34 children younger than five years of age with MPS VI. Mol. Genet. Metab. 109: 62-69. http://dx.doi.org/10.1016/j.ymgme.2013.02.014

Leal GN, de Paula AC, Morhy SS, Andrade JL, et al. (2014). Advantages of early replacement therapy for mucopolysaccharidosis type VI: echocardiographic follow-up of siblings. Cardiol. Young 24: 229-235. http://dx.doi.org/10.1017/ $\underline{S 1047951113000152}$

Litjens T, Baker EG, Beckmann KR, Morris CP, et al. (1989). Chromosomal localization of ARSB, the gene for human $\mathrm{N}$-acetylgalactosamine-4-sulphatase. Hum. Genet. 82: 67-68. http://dx.doi.org/10.1007/BF00288275

McGill JJ, Inwood AC, Coman DJ, Lipke ML, et al. (2010). Enzyme replacement therapy for mucopolysaccharidosis VI from 8 weeks of age--a sibling control study. Clin. Genet. 77: 492-498. http://dx.doi.org/10.1111/j.1399-0004.2009.01324.x

Muenzer J (2014). Early initiation of enzyme replacement therapy for the mucopolysaccharidoses. Mol. Genet. Metab. 111: 63-72. http://dx.doi.org/10.1016/j.ymgme.2013.11.015

Petry MF, Nonemacher K, Sebben JC, Schwartz IV, et al. (2005). Mucopolysaccharidosis type VI: Identification of novel mutations on the arylsulphatase B gene in South American patients. J. Inherit. Metab. Dis. 28: 1027-1034. http://dx.doi. org/10.1007/s10545-005-0020-2

Simonaro CM, Haskins ME and Schuchman EH (2001). Articular chondrocytes from animals with a dermatan sulfate storage disease undergo a high rate of apoptosis and release nitric oxide and inflammatory cytokines: a possible mechanism underlying degenerative joint disease in the mucopolysaccharidoses. Lab. Invest. 81: 1319-1328. http://dx.doi. org/10.1038/labinvest. 3780345

Swiedler SJ, Beck M, Bajbouj M, Giugliani R, et al. (2005). Threshold effect of urinary glycosaminoglycans and the walk test as indicators of disease progression in a survey of subjects with Mucopolysaccharidosis $\mathrm{VI}$ (Maroteaux-Lamy syndrome). Am. J. Med. Genet. A. 134A: 144-150. http://dx.doi.org/10.1002/ajmg.a.30579 